\title{
Cognitions and emotions in eating disorders
}

Citation for published version (APA):

Siep, N., Jansen, A., Havermans, R., \& Roefs, A. (2011). Cognitions and emotions in eating disorders. In R. A. H. Adan, \& W. H. Kaye (Eds.), Behavioral Neurobiology of eating disorders (pp. 17-33). Springer Verlag. Current Topics in Behavioral Neurosciences No. 6 https://doi.org/10.1007/7854_2010_82

Document status and date:

Published: 01/01/2011

DOI:

10.1007/7854_2010_82

Document Version:

Publisher's PDF, also known as Version of record

Document license:

Taverne

Please check the document version of this publication:

- A submitted manuscript is the version of the article upon submission and before peer-review. There can be important differences between the submitted version and the official published version of record.

People interested in the research are advised to contact the author for the final version of the publication, or visit the DOI to the publisher's website.

- The final author version and the galley proof are versions of the publication after peer review.

- The final published version features the final layout of the paper including the volume, issue and page numbers.

Link to publication

\footnotetext{
General rights rights.

- You may freely distribute the URL identifying the publication in the public portal. please follow below link for the End User Agreement:

www.umlib.nl/taverne-license

Take down policy

If you believe that this document breaches copyright please contact us at:

repository@maastrichtuniversity.nl

providing details and we will investigate your claim.
}

Copyright and moral rights for the publications made accessible in the public portal are retained by the authors and/or other copyright owners and it is a condition of accessing publications that users recognise and abide by the legal requirements associated with these

- Users may download and print one copy of any publication from the public portal for the purpose of private study or research.

- You may not further distribute the material or use it for any profit-making activity or commercial gain

If the publication is distributed under the terms of Article $25 \mathrm{fa}$ of the Dutch Copyright Act, indicated by the "Taverne" license above, 
See discussions, stats, and author profiles for this publication at: https://www.researchgate.net/publication/49763575

\section{Cognitions and Emotions in Eating Disorders}

Article in Current Topics in Behavioral Neurosciences · January 2011

Dol: 10.1007/7854_2010_82. Source: PubMed

\section{CITATIONS}

17

4 authors, including:

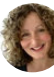

Nicolette Siep

Maastricht University

30 PUBLICATIONS 811 CITATIONS

SEE PROFILE

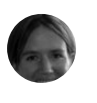

Anne Roefs

Maastricht University

137 PUBLICATIONS 5,579 CITATIONS

SEE PROFILE
READS

617

Anita Jansen

Maastricht University

342 PUBLICATIONS 14,037 CITATIONS

SEE PROFILE

Some of the authors of this publication are also working on these related projects:

PhD Thesis: When surgery alone won't cut it - Physical and psychological influences on weight loss after bariatric surgery View project

STEP-D: the Maastricht Study on the effectiveness, predictors and working mechanisms of cognitive therapy and interpersonal therapy for depression View project 


\title{
Cognitions and Emotions in Eating Disorders
}

\author{
Nicolette Siep, Anita Jansen, Remco Havermans, and Anne Roefs
}

\section{Contents}

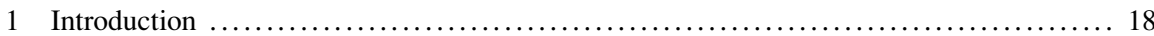

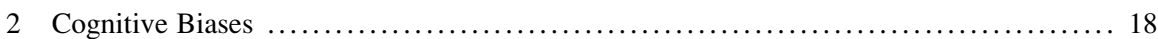

2.1 Attention Bias ...................................................... 19

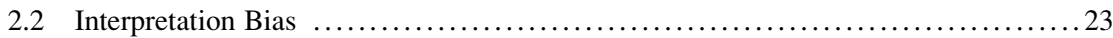

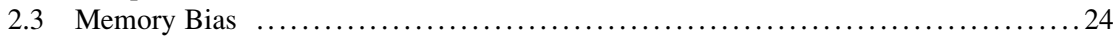

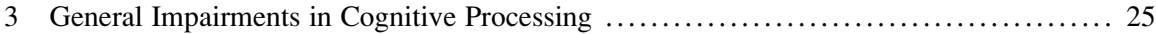

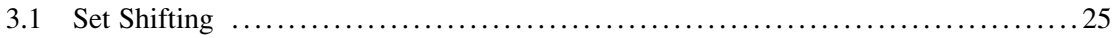

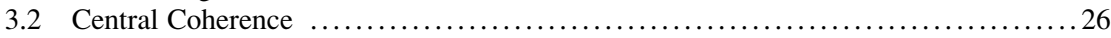

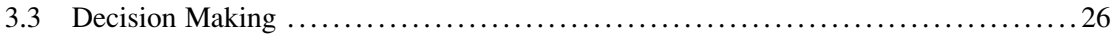

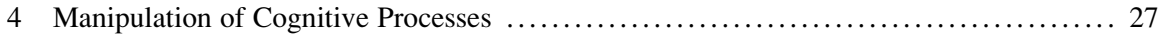

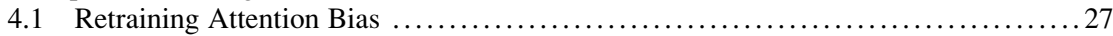

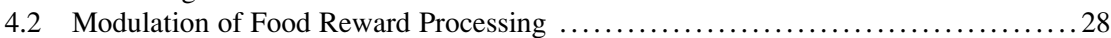

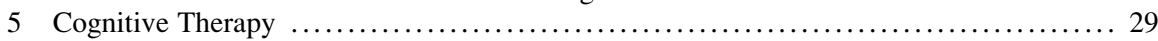

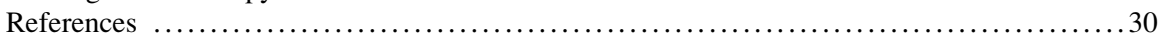

\begin{abstract}
The cognitive model of eating disorders (EDs) states that the processing of external and internal stimuli might be biased in mental disorders. These biases, or cognitive errors, systematically distort the individual's experiences and, in that way, maintains the eating disorder. This chapter presents an updated literature review of experimental studies investigating these cognitive biases. Results indicate that ED patients show biases in attention, interpretation, and memory when it comes to the processing of food-, weight-, and body shape-related cues. Some recent studies show that they also demonstrate errors in general cognitive abilities such as set shifting, central coherence, and decision making. A future challenge is whether cognitive biases and processes can be manipulated. Few preliminary
\end{abstract}

N. Siep ( $₫)$, A. Jansen, R. Havermans, and A. Roefs

Department of Clinical Psychological Science, Faculty of Psychology and Neuroscience, Maastricht University, P.O. Box 616, 6200 MD Maastricht, The Netherlands

e-mail: Nicolette.Siep@maastrichtuniversity.nl 
studies suggest that an attention retraining and training in the cognitive modulation of food reward processing might be effective strategies to change body satisfaction, food cravings, and eating behavior.

Keywords Attention - Body image - Central coherence $\cdot$ Cognitive bias · Craving · Decision-making $\cdot$ Food reward $\cdot$ Interpretation $\cdot$ Memory $\cdot$ Retraining $\cdot$ Set shifting

\section{Introduction}

Imagine that you are sleeping in your bedroom. In the middle of the night you suddenly awake of a loud noise downstairs in the living room. You think "o no, there is a burglar in my house." You feel extremely anxious. You do not dare to go downstairs to have a look in the living room; that is why you stay where you are, trembling, and waiting for what is coming. Now imagine the following situation. You are sleeping again. In the middle of the night you suddenly awake of a loud noise downstairs in the living room. You think "that stupid cat! What did she knock over this time?" You feel a bit irritated but soon continue your sweet dreams. These examples make clear that it is not what is really happening that causes one to feel anxious, irritated, or happy. It is how one interprets what is happening that determines one's feelings. In eating disorders (EDs), it is not one's actual appearance or body weight that causes a problem, but one's evaluation of it. This is a key assumption of the cognitive model of EDs.

\section{Cognitive Biases}

The cognitive model of EDs has its roots in the cognitive model of psychopathology or mental disorders that was formulated by Beck in 1964. Beck theorized that the processing of external events or internal stimuli is biased in mental disorders. These biases, or cognitive errors, systematically distort the individual's experiences. The model points out that eating psychopathology arises from maladaptive knowledge structures (e.g., schemas) that are involved in the allocation of attention, in memory, and in the interpretation of incoming information (Hargreaves and Tiggemann 2002; Williamson et al. 2004). Activation of these knowledge structures causes disorder relevant information to be processed in a biased manner, resulting in a range of cognitive biases in attention, judgment, and memory (Williamson et al. 2004).

In line with Beck's (1976) cognitive specificity hypothesis, Vitousek and Hollon (1990) proposed two decades ago that ED patients consider their own weight and shape as the predominant referents for inferring personal value. Nowadays, this is 
also referred to as "overevaluation" (Fairburn 2008). These cognitions about weight and shape in relationship to the self are organized into structures referred to as weight-related self-schemata. The central premise of the cognitive model is that these schemata are the core cognitive component of EDs. The operation of the schemata might cause and/or maintain EDs by producing systematic errors in weight and shape information processing.

The cognitive model specifies three main cognitive errors in EDs: attention bias, interpretation bias, and memory bias, and some recent studies suggest impairments in general cognitive processing. In this chapter, we will first discuss the main cognitive biases and general impairments in cognitive processing that are demonstrated in EDs. We then will focus on the question whether the manipulation of cognitive processing affects ED psychopathology.

\subsection{Attention Bias}

An attention bias refers to the tendency to selectively attend to disorder relevant stimuli (Mathews and MacLeod 2005). According to the cognitive model of EDs, ED patients are more likely to give priority to cues pertaining to body and foodrelated information than to neutral cues, in comparison to healthy controls. The cognitive model proposes that, with progression of the ED, a phobic orientation toward the body, high-calorie foods, and weight gain develops (Williamson et al. 1999). The hyperattention to disorder relevant cues is presumed to maintain EDs: it might lead to the avoidance of cues that elicit anxiety and negative affect. This avoidance will immediately decrease anxiety, but it will also prevent its extinction. Therefore, in the long run, anxiety and negative effect will maintain or even increase and the ED will continue. Several paradigms have been used to test the attention bias hypothesis in EDs, including the modified Stroop task, the dot-probe task, the visual search task, and eye tracking.

\subsubsection{Stroop Task}

The Stroop task is the most frequently used paradigm to investigate attention bias in ED patients. Neutral words and ED relevant words are printed in different colors (Faunce and Job 2000; Williams et al. 1996). Participants are required to ignore the meaning of the words and to simply report the color in which each word is printed. Disorder relevant words interfere with color naming more than neutral words do, leading to longer color-naming responses for disorder relevant words than for neutral words. This difference in response time for disorder relevant versus neutral words is the "interference effect". Currently, more than 30 studies have evaluated the interference effect for food-, weight-, and shape-related words in ED patients. Confirming the attention bias hypothesis, it was concluded in a meta-analysis that ED patients show increased interference for food-, weight-, and shape-related 
words (Johansson et al. 2005). Both patients with bulimia nervosa (BN) and anorexia nervosa (AN) showed the Stroop interference for weight- and shaperelated words, but AN patients were more interfered by food stimuli relative to BN patients (but see Dobson and Dozois 2004).

Although a large number of studies used the modified Stroop task to demonstrate attention biases in EDs, a number of concerns regarding the use of this task have been raised. In a review of modified Stroop studies in EDs, Lee and Shafran (2004) conclude that Stroop interference with ED-related stimuli is also found in non-ED groups, which brings into question its clinical relevance. More specifically, these biases have been demonstrated in restrained eaters (Francis et al. 1997), hungry participants (Mogg et al. 1998), food deprived participants (Placanica et al. 2002), and in healthy participants who had just finished an appetizer (Overduin et al. 1995). Another, more general, concern about the Stroop task is that little effort has been made to account for the underlying mechanisms of the interference effect (Williams et al. 1996). It is not clear why ED patients show interference. Food, weight, and shape words might trigger anxiety in ED patients, who usually experience strong concerns pertaining to their body weight, shape, and eating, hence making these words especially meaningful and frightening. The anxiety might induce an automatic tendency to avoid further exposure to these words. Interference then might reflect avoidance and not any attention bias. Indeed, De Ruiter and Brosschot (1994) demonstrated that attempts to cognitively avoid the processing of disorder relevant word stimuli also result in increased interference scores.

Thus, the central premise that attention is biased toward food and body stimuli cannot be tested with the modified Stroop task, because it is not clear what the Stroop task precisely measures. Given this uncertainty about the meaning of increased interference scores, no firm conclusions can be drawn about the existence of an attention bias in ED patients using the modified Stroop paradigm. Therefore, alternatives to the Stroop task were used, such as the dot-probe task.

\subsubsection{Dot-Probe Task}

The dot-probe task (MacLeod et al. 1986) is based on the assumption that individuals respond faster to a small dot that is presented in an attended area of a visual display than to a dot that is presented in an unattended area of a visual display. Pairs of pictures or words are concurrently and briefly presented to participants. One word/picture of each pair is disorder relevant and the other is neutral. When the word/picture pair disappears, a small dot appears in a position previously occupied by one of the two words or pictures. The participant is instructed to push a button as quickly as possible when the dot appears. The attention bias for disorder relevant stimuli is calculated by taking the difference in reaction times to the dot when it replaces the neutral stimulus minus reaction times to the dot when it replaces the disorder relevant one. Faster reactions to dots that replace the disorder relevant stimuli indicate an attention bias. 
The first study using the dot-probe task in EDs (Rieger et al. 1998) tested the attention bias for shape-related words. Results showed that the ED group detected a target dot that replaced a thin shape-related word slower than did healthy individuals. In contrast, the ED group detected a target dot that replaced a large shaperelated word faster than did healthy individuals. Rieger and colleagues concluded that ED patients are more likely to attend to information consistent with fatness and to ignore information consistent with thinness, which might maintain distorted cognitions about shape and weight.

Rieger et al. (1998) used words, but Mogg and colleagues argue that using words as stimuli provides a relatively fragile index of attention bias, and they suggest using pictures instead (Mogg et al. 2000). Pictorial dot-probe studies were also done to study ED attention biases (Glauert et al. 2010; Lee and Shafran 2008; Shafran et al. 2007). Using the pictorial dot-probe, Shafran et al. (2007) tested (1) whether attention biases for food-, shape-, and weight-related pictures are stronger in ED participants compared to healthy, anxious, and shape-concerned controls, and (2) whether the strength of attention biases is associated with the severity of ED psychopathology. Stimuli included pictures of food, body shape, body weight, and animals. ED participants were faster to respond to a dot when it replaced negative food and weight pictures, and they responded slower to a dot when it replaced positive food pictures, compared to anxious controls and women with high, moderate, and low levels of shape concerns. In study 2, but not in study 1, ED participants were significantly faster to respond to the dot when it replaced negative and neutral shape pictures compared to the controls. No bias was found for positive shape stimuli. These findings only partially support the previous findings by Rieger et al. (1998). Shafran et al. (2007) suggested that biases for body shapes might be less robust because the pictures were of other persons and hence not personally relevant. In addition, their results showed there was a modest relationship between the degree of psychopathology and the extent of attention biases.

Further research showed that with increasing duration of the interstimulusinterval from 500 to 2,000 ms, the attention bias for food and shape pictures in ED patients disappeared, whereas the bias for weight stimuli remained (Lee and Shafran 2008). These findings suggest a pattern of cognitive avoidance for food and shape pictures that increases over time. This is in line with the cognitive model, stating that the initial attention bias for threatening stimuli eventually serves to enable patients to actively avoid these stimuli. Thus, the attention bias might prevent confrontation with the feared stimulus. If there is no exposure to feared stimuli, fear responses will not be able to extinguish, and in that way the ED will persist. Interestingly, Shafran et al. (2007) showed that attention biases for food, weight, and shape pictures in ED patients decreased after cognitive-behavioral treatment.

\subsubsection{Visual Search Task}

Another method to study attention bias is the visual search task. Treisman and Gelade (1980) devised the first visual search task, in which participants were 
instructed to locate a simple target (e.g., circle, square) as quickly as possible among an array of several distractors, all with a similar shape but different from the shape of the target. Differences in search performance on the visual search task are proposed to reflect differences in the focus of attention. Hansen and Hansen (1988) developed the face-in-the-crowd visual search task in which participants search for an odd face stimulus in a matrix of face stimuli. This adaptation had important advantages. First, if the odd-one-out stimulus is a disorder relevant stimulus, which is presented among neutral distractors, speeded detection of disorder relevant information can be measured. Second, by making the odd-one-out stimulus a neutral stimulus, which is presented among disorder relevant distractors, distraction by disorder relevant information can be measured (Rinck et al. 2005). The distraction component may arguably be similar to maintained attention (Mogg et al. 2005), or slowed disengagement (Fox et al. 2001) components of attention bias. This task thus allows for the investigation of specific mechanisms of attention bias: speeded detection and increased distraction. To our knowledge, so far only one study has applied the odd-one-out visual search task in ED patients (Smeets et al. 2008). In this study, ED participants showed evidence of speeded detection of body shape words, but not of increased distraction by shape stimuli compared to healthy controls. The opposite pattern of results was found for food-related words: ED participants showed no evidence of speeded detection of high-calorie food words, but there was an increased distraction compared to neutral and low calorie words. The finding that ED patients were more distracted by high-calorie words than controls was explained by craving (Mogg et al. 2005; Smeets et al. 2008). Indeed, a substantial number of studies have found significant correlations between attention bias for craving-related stimuli and levels of subjective craving (Field et al. 2005, 2007; Franken et al. 2000; Rosse et al. 1993, 1997). In a next study, Smeets et al. (2009) experimentally induced craving and a causal link between induced chocolate craving and a bias in the distraction component of attention was found. More specifically, when brought to an elevated state of chocolate craving, chocoholics showed more distraction by chocolate than in the absence of such increased chocolate craving state. This study shows that the suggested relationship between craving and attention bias only holds true for the specific distraction component and not for speeded detection.

\subsubsection{Eye Tracking}

Changes in attention usually are directly related to eye movements (Henderson et al. 1989; Rayner 1998). Eye tracking has several advantages over reaction time tasks. It provides a more direct indication of attention bias, and it allows not only to measure the initial detection of a stimulus but also changes in the direction of attention. Also the maintenance of attention on relevant stimuli can be directly assessed by measuring the fixation duration on the stimulus.

Eye tracking studies show that ED patients tend to focus on dissatisfying body parts (Freeman et al. 1991; Jansen et al. 2005). Jansen et al. (2005) showed that ED 
patients allocate their attention more toward their self-identified unattractive body parts than to their self-identified attractive body parts. When looking at the bodies of other persons, the ED patients paid most attention to the other's attractive body parts than to the other's unattractive body parts (upward comparison). Healthy controls, however, did exactly the opposite; they looked more at their own attractive body parts compared to their own unattractive body parts, and they attended more to the other person's unattractive parts than to the other's attractive body parts (downward comparison).

In an additional study, Jansen et al. (2006) showed that control models had a strong positively biased perception of their own attractiveness, whereas ED patients lack this self-serving bias. The cognitive processing in ED patients might have caused this a lack of a self-serving body-image bias, since they focus their attention on body parts that are evaluated as unattractive by themselves whereas healthy controls do the opposite. Mulkens and Jansen (2009) demonstrated that increased attention for appearance leads to increased body dissatisfaction in vulnerable participants (highly body dissatisfied participants), whereas healthy controls show increased body satisfaction after increased attention.

It can be concluded that, in line with the cognitive model of EDs, EDs are characterized by an attention bias for high-calorie foods and bodies. Even if Stroop studies measure biases in attention, they do not clearly indicate how one's attention exactly is biased; is the attention directed at specifically thin bodies, fat bodies, the own body, attractiveness or unattractiveness, and so on. What cognitive processes are involved? And do high-calorie food biases and body biases reflect identical cognitive processes? Use of the dot-probe task suggests that early attention of ED patients is specifically biased toward negative food and body stimuli. The visual search task showed that body stimuli elicit a bias in speeded detection. This task also showed increased distraction by tasty high-calorie food stimuli. It was further demonstrated that craving leads to an attention bias for high-calorie food stimuli more specifically increased distraction. Eye tracking studies demonstrate that the way one inspects bodies is causal to body (dis)satisfaction. EDs specifically focus on their own negatively evaluated body parts, thereby inducing greater body dissatisfaction.

\subsection{Interpretation Bias}

The interpretation bias refers to the tendency to interpret ambiguous stimuli in a disorder relevant way; in EDs, ambiguous stimuli are expected to be interpreted as weight- or shape-related, and in a negative way, especially when these stimuli refer to the patients themselves. Ambiguous scenarios such as "Two friends are giggling and whispering behind you. What do you think they are saying?" are presented. It is assessed how the participant interprets each scenario and whether the interpretation relates to body weight or shape, either in an open-ended or a forced-choice format. 
Cooper (1997) showed that ED patients responded more often with a weight and shape interpretation compared to the healthy controls, both in open-ended and forced-choice negative outcome scenarios referring to themselves. ED patients responded more with positive weight and shape interpretations when the scenarios related to others. Thus, ED patients judge weight and shape to be a more likely explanation for events with a negative outcome and referring to themselves (Cooper 1997; Morrison et al. 2006). Jansen et al. (2007) showed that this was also true for overweight and obese children. Williamson et al. (2000) found that ED patients are able to change interpretations in shape-related situation after explicit instructions. A relevant question for future research is whether retraining interpretations into more positive ones leads to less ED symptoms. It can be concluded that, in line with the cognitive model, EDs are characterized by a self-blaming style, in which they judge weight and shape to be a most likely explanation for negative ambiguous events related to the self. Interestingly, Williamson et al. (2000) showed that it is possible to experimentally manipulate the interpretation bias in ED patients; they demonstrated that interpretations could be made less biased, that is less shape-related (Williamson et al. 2000).

\subsection{Memory Bias}

A memory bias refers to the tendency to recall disorder-specific information more easily. The cognitive model predicts that food, weight, and shape information will be more readily encoded in memory and more easily accessed in recall by ED patients. In general, two types of memory are distinguished: explicit and implicit. Explicit memory is characterized by conscious recollection or recognition of a previous event or experience. In contrast, implicit memory is exhibited when prior experience facilitates or primes performance on a task, without conscious recollection of the experience.

\subsubsection{Explicit Memory Bias}

Research has found convincing support for the existence of an explicit memory bias in ED patients, but data for an implicit memory bias are equivocal (Hermans et al. 1998; Hunt and Cooper 2001; King et al. 1991; Sebastian et al. 1996; Pietrowsky et al. 2002). Studies using paradigms such as the cued and free recall task and the directed forgetting paradigm indicate that EDs show specific explicit ED-related memory biases: EDs show a memory bias for food-, weight-, and shape-related words and not for general emotional words (Hermans et al. 1998; Hunt and Cooper 2001; King et al. 1991; Sebastian et al. 1996; Suslow et al. 2004). It was also found that the memory bias for high-caloric foods was independent of food deprivation in AN participants but not in BN participants (Hunt and Cooper 2001; Pietrowsky et al. 2002; Suslow et al. 2004). 


\subsubsection{Implicit Memory Bias}

To date, as far as the present authors know, only two studies have tested implicit memory in ED patients (Hermans et al. 1998; Johansson et al. 2008). Hermans et al. (1998) used a word-stem completion task but found no differences between AN participants and controls. However, Johansson et al. (2008) argued that the wordstem completion task is not a valid measure of implicit memory, because explicit memory can be used to complete the task. A more valid measure is Jacoby's white noise task (Jacoby et al. 1988). In the white noise task, participants listen to sentences and repeat them out loud. Subsequently, these sentences are presented again, but now they are intermixed with new sentences not previously heard along with background noise that varies in intensity. The participant is instructed to judge the intensity of the background noise. Participants rate noise as less loud for sentences previously heard compared with new sentences, suggesting implicit memory (Jacoby et al. 1988). In agreement with the implicit memory bias hypothesis, Johansson et al. (2008) showed that ED participants rated background noise for food and shape sentences being less loud, compared to neutral sentences. In conclusion, EDs show an explicit memory bias for food, weight, and shape information, and there are some indications for an implicit memory bias in EDs also (but see Hermans et al. 1998).

\section{General Impairments in Cognitive Processing}

In addition to studying the biases proposed by the cognitive model, general processing impairments not specifically related to food, weight, or shape have also been investigated. The general cognitive processes of interest are (1) set shifting, (2) central coherence, and (3) decision making.

\subsection{Set Shifting}

First, cognitive set shifting is considered, which refers to the ability to move back and forth between multiple tasks, operations, or mental sets and is a major component of executive functioning. Problems in set shifting may manifest either as cognitive inflexibility (e.g., concrete and rigid approaches to problem solving) or response inflexibility (e.g., stereotyped behaviors) and have been associated with EDs (Tchanturia et al. 2004a). A systematic meta-analysis shows that both BN and AN participants have problems performing a wide range of cognitive set shifting tasks, for example, the Wisconsin Card Sorting Task (Roberts et al. 2007). Furthermore, it was shown that weight recovery in AN participants did not improve cognitive set shifting, indicating that it is a trait and not a state marker of AN (Tchanturia et al. 2004b). Proposing a genetic basis for impaired cognitive set 
shifting, Holliday et al. (2005) found more set shifting difficulties in healthy sisters of AN patients than in unrelated healthy women. The implication of these findings might be that a therapy improving cognitive flexibility and performance on set shifting tasks in ED patients is beneficial in treatment (Tchanturia et al. 2007).

\subsection{Central Coherence}

The second cognitive ability hypothesized to be impaired in ED is central coherence. A weak central coherence refers to enhanced detailed processing, accompanied by a limited ability to understand context or to "see the big picture." This causes information to be processed in parts, rather than as a whole, which impairs global thinking. Central coherence has been recognized as playing an important role in autism spectrum disorders, and it has now been suggested to also be related to the development of EDs (Happe and Frith 2006; Lopez et al. 2009). Weak central coherence might explain the preoccupation with details and rules observed in many ED patients.

AN patients were also found to have a weaker theory of mind compared to healthy controls (Russell et al. 2009; Harrison et al. 2009). Theory of mind refers to the cognitive ability to understand the internal states of others, and a weak theory of mind is characteristic of autism. However, Oldershaw et al. (2009) demonstrated that recovered AN patients performed significantly better than currently ill AN patients when inferring emotions during a theory of mind task, showing that impaired theory of mind is likely to be caused by self-induced starvation. In a study by Lopez et al. (2009), AN patients and healthy controls completed several tests measuring visuospatial and verbal aspects of central coherence (ReyOsterrieth Complex Figure Test, Embedded Figures Test, Homograph Reading Test, and Sentence Completion Task). Results showed that the AN group scored significantly better on tests requiring local processing and worse on global processing tasks. There was no association between performance and depression, anxiety or degree of starvation. However, weak central coherence was correlated with the number of obsessive-compulsive traits. This fits nicely with the idea of a weak central coherence explaining the anorectic preoccupation with details and rules.

\subsection{Decision Making}

A third cognitive ability that is studied in ED is decision making. ED patients show impaired decision making (Boeka and Lokken 2006; Brand et al. 2007). BN patients performed significantly worse on the Iowa Gambling Task (IGT) and the Game of Dice Task, compared to a control group (Cavedini et al. 2004). There was a significant negative correlation between performance and bulimic symptoms, independent of depressive symptoms (Boeka and Lokken 2006; 
Brand et al. 2007; Cavedini et al. 2004). It was also found that AN patients who had better decision-making abilities at the start of a treatment showed significantly greater improvement in nutritional status (Cavedini et al. 2004). Decision making has been linked to increased impulsivity and overeating (Davis et al. 2004; Nederkoorn et al. 2006).

\section{Manipulation of Cognitive Processes}

It is concluded that ED patients are characterized by cognitive biases and some errors in general cognitive processing. It is not entirely clear whether these biases and impairments in cognitive processes are causes, consequences, or an epiphenomenon of EDs. What happens when the biases are manipulated, for example, by attention retraining? In this section, we discuss some recent studies on the retraining of attention bias and the cognitive modulation of food reward processes.

\subsection{Retraining Attention Bias}

It was discussed above that ED patients show an attention bias for their own unattractive body parts. A first question is whether this way of looking is causal to greater body dissatisfaction. To test causality, Smeets et al. (2010) experimentally manipulated the way of looking in healthy participants and measured its effects on body satisfaction. Results showed that the way one looks at one's own body causes changes in body satisfaction: healthy participants who were trained to attend to their self-defined unattractive body parts showed significantly decreased body satisfaction after the training. It was also showed that slightly body dissatisfied female students who were trained in attending one's own most attractive body parts showed a significant increase in body satisfaction after the training (Smeets et al. 2010). Thus, the way one inspects bodies is causal to body (dis)satisfaction. Retraining the attention bias for negatively evaluated body parts into increased attention for positively evaluated body parts, that is the way healthy females look, was found to be beneficial; this way of looking increased body satisfaction (Smeets et al. 2010). It is of great interest to find out whether such an attention retraining is clinically useful.

Another retraining study focused on inhibitory control (Houben and Jansen 2010). It was studied whether strengthening inhibitory control can increase resistance to high-calorie food temptations. Chocolate cravers were trained to inhibit their responses to chocolate stimuli, which led to significantly reduced chocolate consumption. These findings suggest that strengthening inhibitory control might be an effective strategy to help regain control over food intake. 


\subsection{Modulation of Food Reward Processing}

Food reward stimulates eating behavior (Toates 1986). The incentive salience of food is evaluated in the dopaminergic corticomesolimbic circuitry and motivates eating behavior in the absence of energy deficits (Berridge 2004; Bindra 1978; Bolles 1972). Whether one actually eats - or not - depends on the interaction between food reward and cognitive control (Appelhans 2009). Is it possible to manipulate one's cognitive control in such a way that one is better able to cope with an environment rich in palatable, readily available high-calorie foods? It was therefore studied whether healthy lean women are able to modulate food reward processing using different types of cognitive control strategies (Siep et al. 2010b). Participants were instructed (1) to suppress food palatability thoughts (i.e., do not think about how tasty the food is), (2) to apply cognitive reappraisal (e.g., think about the health consequences of eating it, like gaining weight), and (3) to upregulate thoughts of food palatability (e.g., think about how good the food smells and tastes). It was investigated whether the three cognitive control strategies changed self-reported food cravings and associated food reward activity in the brain as assessed by functional magnetic resonance imaging (fMRI). Both the cognitive reappraisal and suppression manipulations decreased self-reported food cravings compared to upregulation. The fMRI data suggest that these strategies rely on different neural substrates. Cognitive reappraisal decreased activity in the fusiform gyrus (FG) compared to upregulation and suppression, but did not differ from passive viewing in mesocorticolimbic regions. The FG is involved in the processing of visual cues and their reward values, and determines future reward actions (Murray and Izquierdo 2007). The brain responses during cognitive reappraisal suggest that this strategy prevents food cues from eliciting further reward processing. This proposition is in line with the definition of cognitive reappraisal (Gross and John 2003) as "thinking about the emotion eliciting cue in a way that changes its emotion impact." Suppression decreased activity in the ventral striatum (VS) and ventral tegmental area (VTA), and increased activity in the lateral orbitofrontal cortex (OFC) and anterior prefrontal cortex compared to upregulation and suppression. Although suppression successfully inhibited activity in the VS and VTA, the increased prefrontal cortex activity suggests that this strategy requires increased mental effort compared to cognitive reappraisal. As expected, upregulation increased activity in the mesocorticolimbic circuitry. Together these findings show that people can actively up- and downregulate mesocorticolimbic food reward processing, and that craving covaries with the use of cognitive control strategies.

In line with this, one might speculate that $\mathrm{AN}$ is associated with extremely successfully applied cognitive strategies to decrease food reward processing. A cognitive effect of rigid dieting might be the downregulation of food reward activity in the brain. AN might develop when highly controlled, rigid, and obsessively dieting adolescent females overcome the natural rewarding value of food (Pinel et al. 2000). To test the hypothesis of downregulated food reward activity in AN, AN patients were instructed to evaluate the palatability of high and low calorie 
foods and at the same time corticomesolimbic food reward activity was measured (Siep et al. 2010a). Furthermore, it was studied what would happen in the dorsolateral prefrontal cortex (dlPFC) when AN patients focused their attention on a neutral part of the picture while they were simultaneously presented with food pictures. The dlPFC is an area involved in successful self-control (Hare et al. 2009). Interestingly, it was shown that AN patients evaluating high-calorie foods fail to activate two important regions of the corticomesolimbic food reward circuitry: the anterior insular cortex (AIC) and caudal anterior cingulate cortex (cACC). Both the AIC and cACC are involved in craving (Craig 2002, 2003; Naqvi et al. 2007) and in the motivation of reward-related behavior (Walton et al. 2009). Naqvi et al. (2007) showed that smokers who acquire insula damage are likely to stop smoking quite easily. In line with this, it could be hypothesized that a decreased responsiveness of AIC in AN patients allows them to easily stop eating. The AN patients did show increased activity in the right anterior OFC during the palatability evaluation of low calorie foods, supporting the hypothesis of successfully downregulating the food reward processing. In a meta-analysis of neuroimaging studies, Kringelbach and Rolls (2004) concluded that the anterior OFC is involved in the processing of abstract reinforcers such as money. It was concluded that AN patients might evaluate low calorie foods as rewarding but, in contrast to healthy people, their food evaluations appear not to be intuitive (Kaye et al. 2009) or based on palatability (Roefs et al. 2005). To test the proposition of increased dlPFC activity in AN, participants were instructed to focus their attention on a neutral cue while highcalorie foods were simultaneously presented in an unattended part of the stimulus display. This led to a strongly activated dlPFC in AN, but not in healthy controls (Siep et al. 2010a). These findings support earlier ones that show dlPFC hyperactivity in $\mathrm{AN}$, indicating a relatively quick and automatic activation of increased self-control when confronted with high-calorie foods.

\section{Cognitive Therapy}

According to the cognitive model of EDs, ED patients use their own body weight and shape as the predominant factors for inferring personal value. Dysfunctional weight and shape beliefs flow from cognitive structures referred to as schemata. Activation of these schemata produces systematic errors in information processing, such as attention biases, interpretation biases, and memory biases for food and body stimuli. In this way, a negative self-perception is maintained. ED patients show biases in the processing of food-, weight-, and shape-related cues; some recent studies showed that they also demonstrate errors in general cognitive abilities such as set shifting, central coherence, and decision making.

Cognitive behavior therapy (CBT) is up to now the most effective treatment for EDs (see e.g., Wilson et al. 2007). During the cognitive intervention of CBT, dysfunctional cognitions are challenged and a change in thinking is strived for. The assumption is that when thinking changes, emotions will be more positive and 
behavior will be less symptomatic. Future studies might focus on the question whether CBT might profit from incorporating attention retraining to improve body image, attention retraining to strengthen inhibitory control, techniques to change the errors in general cognitive abilities, and training in the manipulation of food reward processing. This of course requires large-scale randomized clinical trials with a so termed additive design. But we would like to contend that the development of progressively efficacious treatments for EDs just as much requires elegant experimental studies such as outlined in the present chapter, experiments that increase our knowledge of the basic mechanisms maintaining eating psychopathology.

\section{References}

Appelhans BM (2009) Neurobehavioral inhibition of reward-driven feeding: implications for dieting and obesity. Obesity 17:640-647

Beck AT (1964) Thinking and depression: theory and therapy. Arch Gen Psychiatry 10:561-571

Beck AT (1976) Cognitive therapy and the emotional disorders. International Universities Press, New York

Berridge KC (2004) Motivation concepts in behavioral neuroscience. Physiol Behav 81:179-209

Bindra D (1978) How adaptive behavior is produced: a perceptual-motivation alternative to response reinforcement. Behav Brain Sci 79:41-91

Boeka AG, Lokken KL (2006) The Iowa gambling task as a measure of decision making in women with bulimia nervosa. J Int Neuropsychol Soc 12:741-745

Bolles RC (1972) Reinforcement, expectancy, and learning. Psychol Rev 79:394-409

Brand M, Franke-Sievert C, Jacoby GE, Markowitsch HJ, Tuschen-Caffier B (2007) Neuropsychological correlates of decision making in patients with bulimia nervosa. Neuropsychology 21:742-750

Cavedini P, Bassi T, Ubbiali A, Casolari A, Giordani S, Zorzi C et al (2004) Neuropsychological investigation of decision-making in anorexia nervosa. Psychiatry Res 127:259-266

Cooper M (1997) Bias in interpretation of ambiguous scenarios in EDs. Behav Res Ther 35: $619-626$

Craig AD (2002) How do you feel? Interoception: the sense of the physiological condition of the body. Nat Rev Neurosci 3:655-666

Craig AD (2003) Interoception: the sense of the physiological condition of the body. Curr Opin Neurobiol 13:500-505

Davis C, Levitan RD, Muglia P, Bewell C, Kennedy JL (2004) Decision-making deficits and overeating: a risk model for obesity. Obesity Res 12:929-935

De Ruiter C, Brosschot JF (1994) The emotional Stroop interference effect in anxiety: attentional bias or cognitive avoidance? Behav Res Ther 32:315-319

Dobson KS, Dozois DJ (2004) Attentional biases in EDs: a meta-analytic review of Stroop performance. Clin Psychol Rev 23:1001-1022

Fairburn CG (2008) Cognitive behavior therapy and EDs. Guilford, New York

Faunce GJ, Job RF (2000) The Stroop colour-naming task and addictive behaviour: some recommendations. Addiction 95:1438-1442

Field M, Mogg K, Bradley BP (2005) Craving and cognitive biases for alcohol cues in social drinkers. Alcohol Alcohol 40:504-510

Field M, Duka T, Eastwood B, Child R, Santarcangelo M, Gayton M (2007) Experimental manipulation of attentional biases in heavy drinkers: do the effects generalise? Psychopharmacology 192:593-608 
Fox E, Russo R, Bowles R, Dutton K (2001) Do threatening stimuli draw or hold visual attention in subclinical anxiety? J Exp Psychol Gen 130:681-700

Francis JA, Stewart SH, Hounsell S (1997) Dietary restraint and the selective processing of forbidden and non-forbidden food words. Cogn Ther Res 21:633-646

Franken IH, Kroon LY, Hendriks VM (2000) Influence of individual differences in craving and obsessive cocaine thoughts on attentional processes in cocaine abuse patients. Addict Behav 25:99-102

Freeman R, Touyz S, Sara G, Rennie C, Gordon E, Beumont P (1991) In the eye of the beholder: processing body shape information in anorexic and bulimic patients. Int J Eat Disord 10:709-714

Glauert R, Rhodes G, Fink B, Grammer K (2010) Body dissatisfaction and attentional bias to thin bodies. Int J Eat Disord 43:42-49

Gross JJ, John OP (2003) Individual differences in two emotion regulation processes: implications for affect, relationships, and well-being. J Pers Soc Psychol 85:348-362

Hansen CH, Hansen RD (1988) Finding the face in the crowd: an anger superiority effect. J Pers Soc Psychol 54:917-924

Happe F, Frith U (2006) The weak coherence account: detail-focused cognitive style in autism spectrum disorders. J Autism Dev Disord 36:5-25

Hare TA, Camerer CF, Rangel A (2009) Self-control in decision-making involves modulation of the vmPFC valuation system. Science 324:646-648

Hargreaves D, Tiggemann M (2002) The effect of television commercials on mood and body dissatisfaction: the role of appaerance-schema activation. J Soc Clin Psychol 21: 287-308

Harrison A, Sullivan S, Tchanturia K, Treasure J (2009) Emotion recognition and regulation in anorexia nervosa. Clin Psychol Psychother 16:348-356

Henderson JM, Pollatsek A, Rayner K (1989) Covert visual attention and extrafoveal information use during object identification. Percept Psychophys 45:196-208

Hermans D, Pieters G, Eelen P (1998) Implicit and explicit memory for shape, body weight, and food-related words in patients with anorexia nervosa and nondieting controls. J Abnorm Psychol 107:193-202

Holliday J, Tchanturia K, Landau S, Collier D, Treasure J (2005) Is impaired set-shifting an endophenotype of anorexia nervosa? Am J Psychiatry 162:2269-2275

Houben K, Jansen A (2010) Training inhibitory control: a recipe for resisting sweet temptations. Manuscript submitted for publication

Hunt J, Cooper M (2001) Selective memory bias in women with bulimia nervosa and women with depression. Behav Cogn Psychother 29:93-102

Jacoby LL, Allan LG, Collins JC, Larwill LK (1988) Memory influences subjective experience: noise judgment. J Exp Psychol Learn Mem Cogn 14:240-247

Jansen A, Nederkoorn C, Mulkens S (2005) Selective visual attention for ugly and beautiful body parts in EDs. Behav Res Ther 43:183-196

Jansen A, Smeets T, Martijn C, Nederkoorn C (2006) I see what you see: the lack of a self-serving body-image bias in EDs. Br J Clin Psychol 45:123-135

Jansen A, Smeets T, Boon B, Nederkoorn C, Roefs A, Mulkens S (2007) Vulnerability to interpretation bias in overweight children. Psychol Health 22:561-574

Johansson L, Ghaderi A, Andersson G (2005) Stroop interference for food- and body-related words: a meta-analysis. Eat Behav 6:271-281

Johansson L, Ghaderi A, Hallgren M, Andersson G (2008) Implicit memory bias for eating- and body appearance-related sentences in EDs: an application of Jacoby's white noise task. Cogn Behav Ther 37:135-145

Kaye WH, Fudge JL, Paulus M (2009) New insights into symptoms and neurocircuit function of anorexia nervosa. Nat Rev Neurosci 10:573-584

King GA, Polivy J, Herman CP (1991) Cognitive aspects of dietary restraint: effects on person memory. Int J EDs 10:313-321 
Kringelbach ML, Rolls ET (2004) The functional neuroanatomy of the human orbitofrontal cortex: evidence from neuroimaging and neuropsychology. Prog Neurobiol 72:341-372

Lee M, Shafran R (2004) Information processing biases in EDs. Clin Psychol Rev 24:215-238

Lee M, Shafran R (2008) Processing biases in EDs: the impact of temporal factors. Int J EDs 41:372-375

Lopez C, Tchanturia K, Stahl D, Treasure J (2009) Weak central coherence in EDs: a step towards looking for an endophenotype of EDs. J Clin Exp Neuropsychol 31:117-125

MacLeod C, Mathews A, Tata P (1986) Attentional bias in emotional disorders. J Abnorm Psychol 95:15-20

Mathews A, MacLeod C (2005) Cognitive vulnerability to emotional disorders. Annu Rev Clin Psychol 1:167-195

Mogg K, Bradley BP, Hyare H, Lee S (1998) Selective attention to food-related stimuli in hunger: are attentional biases specific to emotional and psychopathological states, or are they also found in normal drive states? Behav Res Ther 36:227-237

Mogg K, Bradley BP, Dixon C, Fisher S, Twelftree H, McWilliams A (2000) Trait anxiety, defensiveness, and selective processing of treat: an investigation using two measures of attentional bias. Pers Individ Dif 28:1063-1077

Mogg K, Field M, Bradley BP (2005) Attentional and approach biases for smoking cues in smokers: an investigation of competing theoretical views of addiction. Psychopharmacology 180:333-341

Morrison T, Waller G, Lawson R (2006) Attributional style in the EDs. J Nerv Ment Dis 194:303-305

Mulkens S, Jansen A (2009) Mirror gazing increases attractiveness in satisfied, but not in dissatisfied women: a model for body dysmorphic disorder? J Behav Ther Exp Psychiatry 40:211-218

Murray EA, Izquierdo A (2007) Orbitofrontal cortex and amygdala contributions to affect and action in primates. Ann NY Acad Sci 1121:273-296

Naqvi NH, Rudrauf D, Damasio H, Bechara A (2007) Damage to the insula disrupts addiction to cigarette smoking. Science 315:531-534

Nederkoorn C, Havermans H, Roefs A, Smulders FTY, Jansen A (2006) Impulsivity in obese women. Appetite 47:253-256

Oldershaw A, Hambrook D, Tchanturia K, Treasure J, Schmidt U (2009) Emotional theory of mind and emotional awareness in recovered anorexia nervosa patients. Psychosomatic Med 72:73-79

Overduin J, Jansen A, Louwerse E (1995) Stroop interference and food intake. Int J EDs 18:277-285

Pietrowsky R, Krug R, Fehm HL, Born J (2002) Food deprivation fails to affect preoccupation with thoughts of food in anorectic patients. Br J Clin Psychol 41:321-326

Pinel JP, Assanand S, Lehman DR (2000) Hunger, eating, and ill health. Am Psychol 55:1105-1116

Placanica JL, Faunce GJ, Soames Job RF (2002) The effect of fasting on attentional biases for food and body shape/weight words in high and low ED Inventory scorers. Int J EDs 32:79-90

Rayner K (1998) Eye movements in reading and information processing: 20 years of research. Psychol Bull 124:372-422

Rieger E, Schotte DE, Touyz SW, Beumont PJ, Griffiths R, Russell J (1998) Attentional biases in EDs: a visual probe detection procedure. Int J EDs 23:199-205

Rinck M, Reinecke A, Ellwart T, Heuer K, Becker ES (2005) Speeded detection and increased distraction in fear of spiders: evidence from eye movements. J Abnorm Psychol 114:235-248

Roberts ME, Tchanturia K, Stahl D, Southgate L, Treasure J (2007) A systematic review and metaanalysis of set-shifting ability in EDs. Psychol Med 37:1075-1084

Roefs A, Stapert D, Isabella LA, Wolters G, Wojciechowski F, Jansen A (2005) Early associations with food in anorexia nervosa patients and obese people assessed in the affective priming paradigm. Eat Behav 6:151-163

Rosse RB, Miller MW, Hess AL, Alim TN, Deutsch SI (1993) Measures of visual scanning as a predictor of cocaine cravings and urges. Biol Psychiatry 33:554-556 
Rosse RB, Johri S, Kendrick K, Hess AL, Alim TN, Miller M et al (1997) Preattentive and attentive eye movements during visual scanning of a cocaine cue: correlation with intensity of cocaine cravings. J Neuropsychiatry Clin Neurosci 9:91-93

Russell TA, Schmidt U, Doherty L, Young V, Tchanturia K (2009) Aspects of social cognition in anorexia nervosa: affective and cognitive theory of mind. Psychiatry Res 168:181-185

Sebastian SB, Williamson DA, Blouin DC (1996) Memory bias for fatness stimuli in the EDs. Cogn Ther Res 20:275-286

Shafran R, Lee M, Cooper Z, Palmer RL, Fairburn CG (2007) Attentional bias in EDs. Int J EDs 40:369-380

Siep N, Roefs A, Roebroeck A, Havermans R, Bonte ML, Jansen A (2010a) Decreased mesocorticolimbic food reward processing and increased dorsolateral cognitive control in Anorexia Nervosa patients. Paper submitted for publication

Siep N, Roefs A, Roebroeck A, Havermans R, Bonte ML, Jansen A (2010b). The regulation of mesocorticolimbic food reward processes through cognitive control. Paper submitted for publication

Smeets E, Roefs A, van Furth E, Jansen A (2008) Attentional bias for body and food in EDs: increased distraction, speeded detection, or both? Behav Res Ther 46:229-238

Smeets E, Roefs A, Jansen A (2009) Experimentally induced chocolate craving leads to an attentional bias in increased distraction but not in speeded detection. Appetite 53:370-375

Smeets E, Jansen A, Lindelauf T, Roefs A (2010) Selective attention for unattractive body parts causes body dissatisfaction. Paper submitted for publication

Suslow T, Ohrmann P, Lalee-Mentzel J, Donges US, Arolt V, Kersting A (2004) Incidental learning of food and emotional words in women with anorexia nervosa. Eat Weight Disord 9:290-295

Tchanturia K, Anderluh MB, Morris RG, Rabe-Hesketh S, Collier DA, Sanchez P et al (2004a) Cognitive flexibility in anorexia nervosa and bulimia nervosa. J Int Neuropsychol Soc 10:513-520

Tchanturia K, Morris RG, Anderluh MB, Collier DA, Nikolaou V, Treasure J (2004b) Set shifting in anorexia nervosa: an examination before and after weight gain, in full recovery and relationship to childhood and adult OCPD traits. J Psychiatry Res 38:545-552

Tchanturia K, Davies H, Campbell IC (2007) Cognitive remediation therapy for patients with anorexia nervosa: preliminary findings. Ann Gen Psychiatry 6:14

Toates F (1986) Motivational systems. Cambridge University Press, Cambridge, MA, USA

Treisman AM, Gelade G (1980) A feature-integration theory of attention. Cogn Psychol 12:97-136

Vitousek K, Hollon S (1990) The investigation of schematic content and processing in EDs. Cogn Ther Res 14:191-214

Walton ME, Groves J, Jennings KA, Croxson PL, Sharp T, Rushworth MF et al (2009) Comparing the role of the anterior cingulate cortex and 6-hydroxydopamine nucleus accumbens lesions on operant effort-based decision making. Eur J Neurosci 29:1678-1691

Williams JM, Mathews A, MacLeod C (1996) The emotional Stroop task and psychopathology. Psychol Bull 120:3-24

Williamson DA, Muller SL, Reas DL, Thaw JM (1999) Cognitive bias in EDs: implications for theory and treatment. Behav Modif 23:556-577

Williamson DA, Perrin L, Blouin DC, Barbin JM (2000) Cognitive bias in EDs: interpretation of ambiguous body-related information. Eat Weight Disord 5:143-151

Williamson DA, White MA, York-Crowe E, Stewart TM (2004) Cognitive-behavioral theories of EDs. Behav Modif 28:711-738

Wilson GT, Grilo CM, Vitousek KM (2007) Psychological treatment of EDs. Am Psychol 62:199-216 


\section{丵 Springer}

http://www.springer.com/978-3-642-15130-9

Behavioral Neurobiology of Eating Disorders

(Eds.)R.A.H. Adan; W.H. Kaye 2011, XIII, 330 p., Hardcover

ISBN: 978-3-642-15130-9 